Alkali was added to Sample 1 at 9.00 A.M., 1.73 per cent. glycogen found. Alkali was added to Sample 2 at 9.15 A.M., 1.76 per cent glycogen found. Alkali was added to Sample 3 at 9.30 A.M., 1.71 per cent. glycogen found.

The following morning (3/25/'o8) triplicate samples were taken, temperature did not exceed $6^{\circ} \mathrm{C}$.

Alkali added to Sample 1 at 9.45 A.M. 1.65 per cent. glycogen found. Alkali added to Sample 2 at 10.00 A.M., 1.70 per cent. glycogen found. Alkali added to Sample 3 at 10.15 A.M., 1.73 per cent. glycogen found.

In the evening (3/25/'o8) a sample was weighed out at a temperature of $8^{\circ} \mathrm{C}$, which gave 1.67 per cent. glycogen. These results indicate that at $10^{\circ} \mathrm{C}$. or lower no appreciable hydrolysis of the glycogen takes place. This problem is to be studied further during the ensuing year.

Columbia, Missouri

[CONTRIBUTION FROM THE HAVEMEYER LABORATORIES OF COLUMBIA UNIVERSITY. No. 175.]

\section{A SOURCE OF ERROR IN THE EXAMINATION OF FOODS FOR SALICYLIC ACID.}

By H. C. SHERMAN.

Received September 20, 1909.

In testing foods for preservatives it is commonly assumed that a constituent volatile with steam, soluble in ether, capable of sublimation and crystallization, and giving a violet reaction with ferric chloride, must be salicylic acid. This assumption is, however, incorrect.

It has recently come to the attention of the writer that certain baked cereal products and prepared foods containing such products yield a constituent which shows all of these properties and which would therefore, upon ordinary examination, cause these foods to be reported as containing salicylic acid; but further study showed that the constituent in question did not come from the raw materials used but was developed during the baking process. Salicylic acid was in fact absent and the source of error was indicated by an examination of the literature of the ferric chloride test for salicylic acid and was fully demonstrated by experiment.

\section{LITERATURE.}

Brand found, in $1893,{ }^{1}$ that an extract of caramel malt gave a reaction with ferric chloride like that given by salicylic acid, and in a paper published the following year ${ }^{2}$ cites Erich $^{3}$ and Munsche ${ }^{4}$ as having made the same observation. In his paper of $1894,{ }^{2}$ Brand recorded the actual separation from such caramel malt of a crystalline substance, soluble in ether or water (much less soluble in cold water than hot), volatile with steam, capable of sublimation and reacting like salicylic acid with ferric chloride, but which did not give the red reaction of salicylic acid with Millon's reagent. By condensing the vapors given off during the roasting process in the manufacture

\footnotetext{
1 tschr. f. d. ges. Brauw. 15, 303

2 Ber., 27, 806.

${ }^{8}$ Der Bierbratuer, 24, 465.

4 Woch. f. Brauerei, 10, 739 .
}

of a so-called malt coffee, extracting with ether, purifying and recrystallizing in different ways, Brand obtained the reacting substance in crystalline form both as leaflets and as needles. Brand named the substance "maltol," and showed that it had phenolic character and agreed with the formula $\mathrm{C}_{6} \mathrm{H}_{6} \mathrm{O}_{3}$.

Kiliani and Bazlen ${ }^{1}$ also prepared maltol in crystalline form, showed that it has an acid reaction, and studied its chemical behavior.

Will ${ }^{2}$ studied its effect upon yeast.

Abraham $^{3}$ pointed out that dark-colored beers may readily contain maltol which, in the examination of the beer for preservatives, will behave like salicylic acid, both in steam distillation and extraction with ether, and give a marked violet coloration with ferric chloride. The ferric chloride reaction being thus inapplicable and the Millon reaction not suitable, Abraham recommended the Jorissen reaction.

This reaction for salicylic acid, proposed by Jorissen in 1882,4 is as follows :

Jorissen's Reaction.-To the solution to be tested add 4 or 5 drops of a ten per cent. solution of potassium (or sodium) nitrite, 4 or 5 drops of acetic acid, I drop of a ten per cent. solution of copper sulphate and heat to boiling. In the presence of salicylic acid the solution turns reddish and with more than a very minute amount becomes blood-red. According to Jorissen phenol behaves in the same way but benzoic acid does not. Abraham found that maltol does not give this reaction and recommended it as the most reliable test for salicylic acid.

da Silva ${ }^{5}$ used Jorissen's reaction among others.

Klett ${ }^{\beta}$ recommends Jorissen's reaction for the detection of salicylic acid in substances containing citric acid.

Jorissen's reaction was one of those used by Portes and Desmoulieres ${ }^{7}$ as demonstrating the presence of small amounts of salicylic acid in strawberries.

Windsch, ${ }^{8}$ investigating the natural occurrence of salicylic acid in fruits, and having obtained violet reactions with ferric chloride from raspberries and strawberries, adopted the Jorissen reaction to decide the question whether the reacting substance was actually salicylic acid.

Thus it is evident that the Jorissen reaction for the detection of salicylic acid is fairly well established in Europe.

\footnotetext{
1 Ber., 27, 3115.
}

${ }^{2}$ Ztschr. ges. Brauw., 21, 307; abs. Ztschr. Unters. Nahr. Genussm., 1, 720 .

3 Journ. de Pharmacie, de Liege, 1898, 5, 173. Abstracted in Repert Pharm. [3], 10, 347, and $Z$ tschr. Unters. Nahr. Genussm., 1, 857.

4 Bulletins de l'Academie Royal des Sciences. des Lettres, et des Beauxarts de Belqique. 3rd series, 3, 259.

${ }^{5}$ Compt. rend., 131, 423 (1900); Bull. soc. chim. [3], 23, 795 (1900)

${ }^{\circ}$ Pharm. Centr., 41, 452; Ztschr. Unters. Nahr. Genussm., 4, 469. 5,468 .

7 Annal. chim, analyt., 6, 401 (1901); Ztschr. Unters. Nahr. Genussm.,

${ }^{8}$ Ztschr. Unters. Nahr Genussm., 6, 447. 


\section{EXPERIMENTAL.}

Fifty grams of a prepared food consisting in part of a baked cereal product were mixed with water, acidulated with phosphoric acid and distilled with steam in an Erlenmeyer flask surrounded by oil heated to $120^{\circ}-130^{\circ}$. Portions of distillate tested from time to time gave distinct violet reaction with ferric chloride, but no reddish color in Jorissen's test. The distillation was continued until the ferric chloride reaction was no longer obtained, when the total distillate measured $800 \mathrm{cc}$. When this was mixed and one-hundredth of it $(8 \mathrm{cc}$.) tested with ferric chloride a distinct reaction like that of salicylic acid was obtained. That the reacting substance was not salicylic acid was shown by extracting thoroughly the other ninetynine-hundredths of the distillate with ether, treating it as recommended by the Association of Official Agricultural Chemists ${ }^{1}$ for the complete recovery of salicylic acid, subliming and testing the product obtained. Although this represented practically one hundred times as much of the substance as had last been tested and found to react with ferric chloride, no reaction whatever was obtained with the Jorissen test.

Comparative tests with known solutions indicated that in the writer's hands about twice as much salicylic acid is required for the Jorissen reaction as for the reaction with ferric chloride, whereas in the above case a distinct coloration was obtained with ferric chloride in a test representing 0.5 gram of the sample and no coloration when the Jorissen reaction was applied to a solution of about equal volume, which represented about 50 grams of the same sample, or about one hundred times as much. Hence if the reaction with ferric chloride in the first case had been due to salicylic acid there would have been present in the second case about $5^{\circ}$ times as much as is required to give a distinct coloration with the Jorissen reaction. It is therefore abundantly evident that the substance which gave the violet reaction with ferric chloride was not salicylic acid. It was probably Brand's maltol or some very similar substance. The production of this substance is evidently due to the baking process or caramelization rather than to the presence of malt, though it may be produced more abundantly in the baking of malt than in the baking of flour.

When 25 grams of the brown outer crust of ordinary wheat bread (partly from "patent" and partly from "whole wheat" flour) were treated in the same manner as the prepared food described above, the distillate gave a distinct violet reaction with ferric chloride, though it was, of course, free from salicylic acid and did not give the Jorissen reaction.

It may also be noted that Abraham ${ }^{2}$ obtained the

\footnotetext{
${ }_{1}$ Bull. 107 (Revised), Bur. Chem., U. S. Dept. Agriculture.

2 Loc. cit.
}

violet (maltol) reaction with ferric chloride from roasted coffee as well as from caramel malt.

\section{SUMMARY.}

Maitol, an acid substance volatile with steam, soluble in ether, capable of sublimation, crystallizing sometimes in leaflets and sometimes in needles, and giving with ferric chloride the same violet color as salicylic acid has been shown to be formed in the baking or roasting of malt and the same or some similar substance is produced in the roasting of coffee and the baking of wheat bread.

Such a substance would be reported as salicylic acid when the present ferric chloride test is used, no matter how carefully the test be made and even if the precaution be taken to sublime the acid and a crystalline sublimate be obtained.

In order to avoid this source of error some reaction other than that with ferric chloride must be used for the detection of salicylic acid in foods. Jorissen's reaction, already well established in European literature, is not subject to the same source of error. In carrying out this reaction about Io $\mathrm{cc}$. of the liquid to be tested were used and to this were added 4 or 5 drops of ten per cent. potassium nitrite, 4 or 5 drops of fifty per cent. acetic acid, I drop of ten per cent. copper sulphate; the liquid, after shaking, was then heated to boiling and, if necessary, boiled for half a minute and allowed to stand one or two minutes for the red color to develop. Under these conditions 0.00005 gram of salicylic acid in Io cc. water ( $\mathrm{I}$ : 200,000 ) gives a distinct reddish color, easily recognizable after a very little practice, especially on comparison with a blank test carefully made with the same amounts as the reagents. With larger amounts of salicylic acid an unmistakable blood-red color develops quickly on heating.

September 14, 1909.

\section{ADDRESSES.}

\section{A NEW STEP IN INDUSTRIAL EDUCATION.'}

\author{
By Allen Rogers, Ph.D.
}

At the present time when there is so much being said in the daily papers and magazines in regard to industrial education, it may be of interest to give an outline of what we are doing at Pratt Institute, and what we hope to do in the future.

Before undertaking, however, to describe what we are doing, I should like to point out two things that we do not attempt. In the first place we are not a trade school; that is, we do not claim to graduate men who are fitted to do only one kind of work. On the other hand we are far removed from the ordinary technical school or university. Although we may teach the same or similar subjects as given in trade or technical schools, we approach them in an entirely different manner, while the attitude of our students toward their work is also quite different. Our field, therefore, may be said to lie practically half way between the two.

In describing the aims of this course in Applied Chemistry, 1908.
1 Read at New Haver Meeting, American Chemical Society, July 1 , 